\title{
LA PRIMERA EXPOSICIÓN DE ESCULTURAS CELEBRADA EN EL REAL MUSEO DE PINTURAS *
}

\author{
POR
}

ISADORA ROSE-DE VIEJO

\begin{abstract}
Documentos conservados en los archivos del Museo del Prado y del Palacio Real, un anuncio aparecido en el Diario de Madrid y el testimonio de un forastero, revelan que las primeras esculturas expuestas en el entonces todavía denominado Real Museo de Pinturas durante quince días de enero de 1827, fueron dos estatuas sedentes de cuerpo entero ejecutadas en Roma: el Carlos IV (1817) de Ramón Barba y la María Luisa de Parma (1816) de José Álvarez Cubero. Esto debió ser un acontecimiento cultural y político que hasta ahora no se había recogido en la literatura sobre la historia del museo.

Palabras clave: Museo del Prado; Carlos IV; María Luisa de Parma; José Álvarez Cubero; Ramón Barba; Escultura neoclásica española; S. XIX.

Documents preserved in the archives of the Prado Museum and the Madrid Royal Palace, an announcement in the Diario de Madrid and the testimony of a foreign resident, reveal that the first sculptural works exhibited in the then still denominated Royal Painting Museum for a period of fifteen days in January 1827 , were two full-length seated portrait statues executed in Rome: Carlos IV (1817) by Ramón Barba and María Luisa de Parma (1816) by José Álvarez Cubero. This must have been a major cultural and political event that until now had not been noted in the literature on the history of the museum.

Key words: Prado Museum; Carlos IV; María Luisa de Parma; José Álvarez Cubero; Ramón Barba; Spanish neo-classical sculpture; $19^{\text {th }}$ century.
\end{abstract}

Mientras residía en Madrid, llegaron de Roma estatuas de Carlos IV y su reina María Luisa, bellamente labradas por artistas españoles.

Alexander SLIDELL-MackenZIE

Las memorias de Alexander Slidell-Mackenzie (Nueva York, 1803-1848), un joven teniente de navío de la Marina americana que residió en Madrid entre noviembre de 1826 y abril de

* Por su ayuda fundamental, deseo dar las gracias muy especialmente a Pilar Benito del Patrimonio Nacional y Mercedes Orihuela del Museo del Prado. También agradezco su ayuda en búsquedas puntuales a Rocío Arnáez, Andrés Gutiérrez, José Manuel Matilla, Emir Moreno y Cecilia San Juan (todos del Museo del Prado); Pilar Lizán (Biblioteca de Historia, CSIC); Isabel Ortega (Biblioteca Nacional); Ana María Gutiérrez y Carlos Teixidor (Archivo Ruiz Vernacci); Angela Jimena Pinilla (Archivo Moreno); Rafael Villareal (Archivo General del Palacio Real); y Priscilla E. Muller (The Hispanic Society of America).

AEA, LXXVIII, 2005, 309, pp. 59 a 69 
1827 con el propósito de aprender español, no engañan ${ }^{1}$. Al contrario, informan sobre lo que debió constituir un acontecimiento cultural y político notable de la época fernandina: la exposición por primera vez al público de dos grandes estatuas neoclásicas de los Reyes Padres - obras en aquel tiempo propiedad de su hijo- en el distinguido marco del entonces aún denominado Real Museo de Pinturas. Documentos localizados en los archivos del Museo del Prado y del Palacio Real de Madrid ${ }^{2}$ que se complementan entre sí, demuestran la veracidad de los recuerdos que de tan singular evento anotó el marinero-escritor, un forastero de 23 años por lo demás poco relacionado con los personajes de la Corte y escasamente enterado de sus intrigas.

En efecto, el 14 de agosto de 1826 llegaron a la Real Aduana de Madrid procedentes de la de Barcelona, a donde habían arribado por barco desde Italia, dos estatuas sedentes de cuerpo entero que representaban a Carlos IV y María Luisa de Parma, obras ejecutadas en Roma pocos años antes del fallecimiento de estos monarcas en el exilio por los escultores Ramón Barba (1767-1831) y José Álvarez Cubero (1768-1827), respectivamente (Figs. 1 y 2) ${ }^{3}$. El transporte terrestre había sido encargado a Antonio Navas, «Carromatero de la Ciudad de Barcelona», quien cobró 12.060 reales en dos plazos, más otros 500 de «ayuda de costa» ${ }^{4}$. Las dos cajas que contenían las esculturas, de 402 arrobas de peso total (4.624 kilos), permanecieron en la Aduana de la Corte durante cinco días, hasta el 19 de agosto, fecha en que, cumpliendo lo estipulado por la Real Orden del día 16 — «que ... se coloquen en el Edificio del Real Museo de Pinturas»—, fueron conducidas allí bajo la custodia de Álvarez, Primer Escultor de Cámara y de regreso en España desde el mes mayo, quien encargó «la construcción de unos bancos proporcionados para colocarlas, al sacarlas de los Cajones.» Álvarez se comprometió asimismo a examinar los objetos artísticos por «si por razon del viaje por mar, ó por haber estado almazenados [sic] mucho tiempo es necesario limpiarlos ó hacer alguna otra operación ${ }^{5}$, como indicaba en la misma carta dirigida al Encargado del Despacho de Mayordomía Mayor, Francisco Blasco ${ }^{6}$. Afortunadamente, las estatuas no habían padecido ningún percance durante el largo viaje por mar y tierra, y se pudo informar «que han llegado á esta Corte sin el menor deterioro» ${ }^{7}$. El 3 de septiembre ya se encontraban «limpias y corrientes para poderlas manifestar al publico», según señala el Director en comisión del Museo, el recién nombrado duque de $\mathrm{Hijar}^{8}$, en otro informe enviado a Blasco 9 .

La intención inicial de mostrar estas obras públicamente - planteada personalmente por el duque de Hijar a Fernando VII durante el verano de 1826 - consistió lógicamente en «condu-

\footnotetext{
${ }^{1}$ Alexander Slidell-Mackenzie, A Year in Spain by a Young American, 2 tomos. Londres, 1831 [1 ${ }^{\text {a }}$ ed. Boston, 1829], II, p. 317. Para datos biográficos véase: «Mackenzie, Alexander Slidell», en Encyclopedia Americana. International Edition, 30 tomos (Nueva York, 1965), t. 18, p. 67.

${ }^{2}$ Archivo del Museo del Prado [AMP], caja 357, leg. 46, núm. 25 (7 documentos fechados entre el 16/VIII/1826 y el 20/I/1827). Archivo General del Palacio Real de Madrid [AGP], Sección de Administración General [AG], leg. 41, exp. 126; AGP, Expediente Personal [EP] de José Álvarez, caja 67, exp. 3.

${ }^{3}$ Carlos IV: Museo del Prado, núm. E-899; 1817, mármol de Carrara, altura $180 \mathrm{~cm}$, anchura $100 \mathrm{~cm}$, profundidad 130 cm; depositado en Patrimonio Nacional, inv. núm. 50000029; sostiene una lanza en la mano derecha. María Luisa de Parma: Museo del Prado, núm. E-902; 1816, mármol de Carrara, altura $140 \mathrm{~cm}$, anchura $75 \mathrm{~cm}$, profundidad $80 \mathrm{~cm}$; depositado en Patrimonio Nacional, inv. núm. 50000030; sostenía un cetro en la mano derecha, ahora perdido.

${ }^{4}$ AGP, AG, leg. 41, exp. 126, docs. 1 y 2; AGP, EP, José Álvarez, caja 67, exp. 3, doc. 69: informe de Ballesteros a Blasco (14/VIII/1826).

${ }^{5}$ AGP, EP, José Álvarez, caja 67, exp, 3, doc. 73: Álvarez a Blasco (19/VIII/1826).

${ }^{6}$ 1771-1835, funcionario de confianza de Fernando VII (AGP, EP, Francisco Blasco, caja 2678, exp. 38).

${ }^{7}$ AGP, EP, José Álvarez, caja 67, exp. 3, doc. 72: Blasco a Manuel de Carranza, Director General de Rentas.

${ }^{8}$ José Rafael Fadrique Fernández de Hijar, Silva, Palafox y Centurión et al, Duque de Hijar, Marqués de Orani, Conde de Aranda, de Rivadeo y de Salvatierra et al, seis veces Grande de España de primera clase (m. 1868), juró el cargo de Sumiller de Corps el 7 de mayo de 1824, y el 3 de mayo de 1826 fue nombrado Director en comisión del Real Museo, donde continuó en el cargo de Director hasta 1838 (AGP, EP, José Rafael Fadrique, caja 512, exp. 12).

${ }^{9}$ AMP, caja 357, leg. 46, núm. 25: Hijar a Blasco (3/IX/1826).
}

AEA, LXXVIII, 2005, 309, pp. 59 a 69 

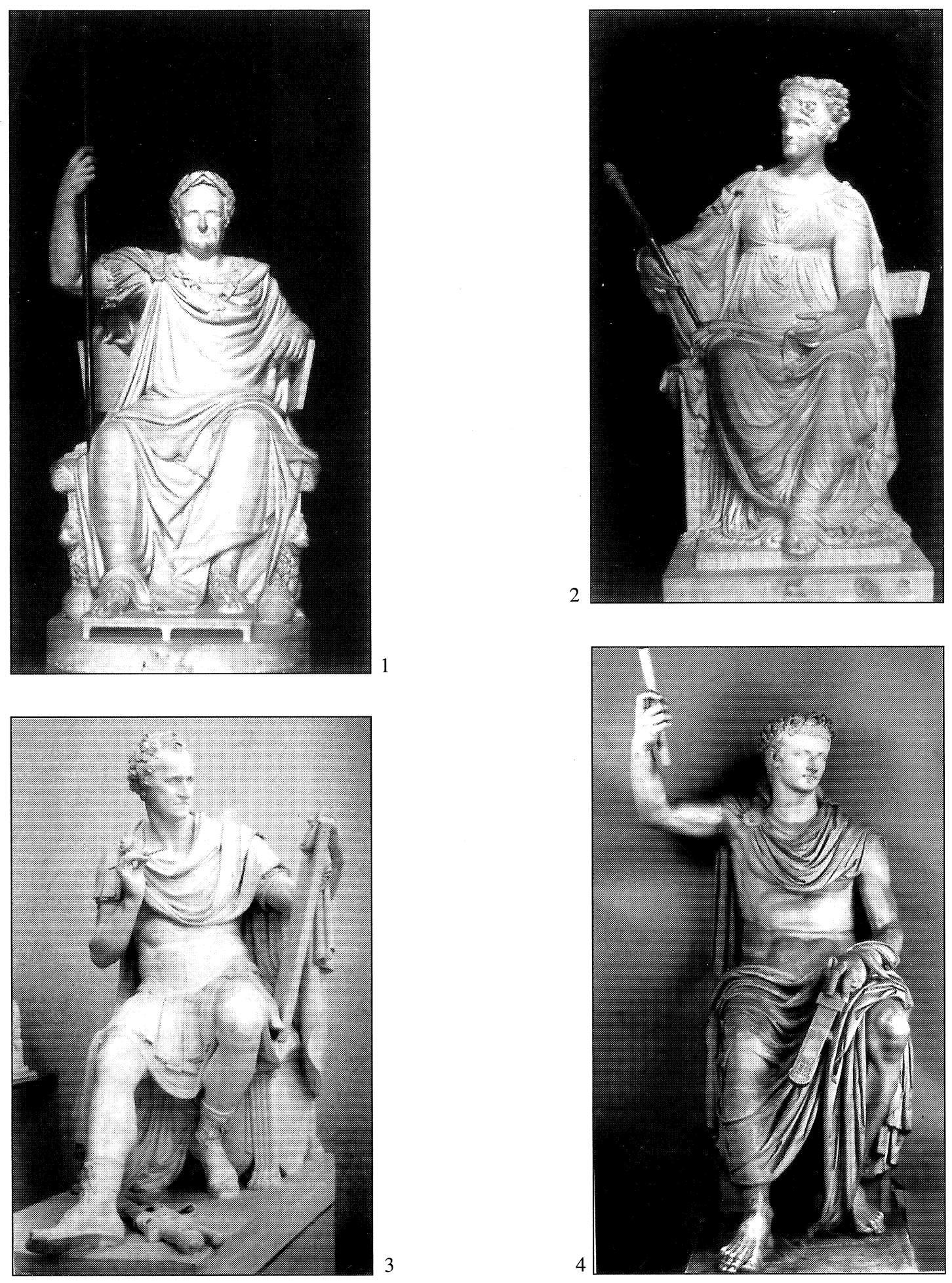

Fig. 1. Ramón Barba, Carlos IV, sedente, 1817, mármol de Carrara, en una fotografía de h. 1862, Museo del Prado, núm. E-899.

Fig. 2. José Álvarez Cubero, María Luisa de Parma, sedente, 1816, mármol de Carrara, en una fotografía de h. 1862, Museo del Prado, núm. E-902.

Fig. 3. Antonio Canova, George Washington, 1817, yeso, Gipsoteca Canoviana, Possagno, núm. 265.

Fig. 4. Anónimo romano, Tiberio, h. 14-37 d.C., mármol, Museo Chiaramonti, Vaticano, Roma, núm. 400.

AEA, LXXVIII, 2005, 309, pp. 59 a 69 
cirlas á la R. ${ }^{l}$ Academia de Nobles Artes para la proxima exposicion», pero este propósito se vió frustrado por la falta de espacio para su adecuada presentación dentro de la Academia de San Fernando. El director del Real Museo manifestaba en su informe que «habiendo examinado este edificio no hay en el mas punto para colocarlas que en el Patio», pero descartaba esta posibilidad porque consideraba que éste no sería un sitio «decente ni propio para el decoro que es justo tributar a los dos soberanos que representan». Así que recomendó su colocación «en la prim. ${ }^{a}$ rotunda [sic] del mismo establecimiento del Museo de Pinturas a donde podran acudir los nacionales y extrangeros que quieran examinar la belleza de estas obras». El Rey, no obstante, determinó en una comunicación fechada el 10 de septiembre que, por el momento, debían de permanecer en el museo pero «sin manifestarles al publico» ${ }^{10}$.

No hay más noticias documentales hasta el 19 de enero de 1827, cuando Fernando VII aceptó al fin la propuesta formulada por el duque de Hijar a comienzos de septiembre. A la vez, el Soberano aprobó la publicación de un aviso al efecto en el Diario de Madrid, cuyo texto, emitido por la dirección del museo, fue enviado a Antonio Galindo, Corregidor interino de la Villa, el mismo día $19^{11}$. Galindo acusó recibo con fecha del 20, garantizando que el anuncio saldría «sin falta alguna...en el dia 21 del corr. ${ }^{t e} »$, de suerte que el aviso apareció recopilado al pie de la letra en el Diario de Avisos de Madrid del domingo 21 de enero de 1827, primera página (p. 81 del año en curso):

«Dirección de [sic] real Museo de pinturas. El Rey nuestro Señor se ha dignado conceder su real permiso para que se manifiesten al público por término de quince dias dos estatuas, que representan á sus augustos padres los Sres. D. Carlos IV y doña María Luisa, ejecutadas en Roma por los escultores de cámara D. José Alvarez y D. Ramon Barba. Las personas que quieran examinar el mérito artístico de estas obras podrán pasar á verificarlo al real Museo de pinturas desde las diez de la mañana hasta las tres de la tarde de los quince dias que S.M. ha señalado, empezando desde mañana 22 del corriente».

Así que la exposición duró desde el 22 de enero hasta el 5 de febrero de 1827.

Las estatuas fueron emplazadas en un lugar de honor - la rotonda de entrada (actualmente la rotonda norte, detrás de la puerta alta de Goya)—, que en la época constituía el único punto de acceso a las pocas salas de pinturas acondicionadas para ser visitadas, situadas en el lado norte de la planta principal del edificio ${ }^{12}$. Sorprendentemente, a pesar de la extensa literatura publicada sobre la historia del Museo del Prado ${ }^{13}$ y de los estudios editados relativos a

\footnotetext{
${ }^{10}$ AMP, caja 357, leg. 46, núm. 25: Hijar a Blasco (3/IX/1826); Blasco a Hijar (10/IX/1826).

11 AMP, caja 357, leg. 46, núm. 25: «Aviso para el Diario» (19/1/1827).

12 Véase los quatro primeros catálogos de obras expuestas en el Real Museo redactados por Luis Eusebi: Catálogo de los Cuadros de Escuela Española que existen en el Real Museo del Prado (Madrid, 1819); Catálogo de los Cuadros que existen Colocados en el Real Museo del Prado (Madrid, 1821); Catálogo de los cuadros que existen colocados en el Real Museo de Pinturas del Prado (Madrid, 1824); y Noticia de los cuadros que se hallan colocados en la Galería del Museo del Rey nuestro Señor, sito en el Prado de esta Córte (Madrid, 1828), en la cual explica (p. 3): «El Museo del Rey...está dividido actualmente en cuatro partes. En los dos salones grandes que se encuentran á derecha é izquierda del magnífico vestíbulo, están colocados los cuadros de la escuela Española antigua. La primera division á la entrada de la gran Galería del medio contiene provisionalmente los de escuela Española pintados por artistas que aun existen, ó que fallecieron hace poco tiempo». Véase también: Alfonso Emilio Pérez Sánchez, Pasado, presente y futuro del Museo del Prado, Fundación Juan March (Madrid, 1977), p. 19; Pedro Moleón Gavilanes, Proyectos y obras para el Museo del Prado. Fuentes documentales para su historia. Museo del Prado (Madrid, 1996); y Pedro Moleón Gavilanes, «El Museo del Prado. Biografía constructiva», en Lecciones sobre el Museo de Prado, Fundación Juan March (Madrid, 1999), pp. 11-35.

${ }^{13}$ Véase, por ejemplo: Pedro Beroqui, El Museo del Prado. Notas para su historia. El Museo Real 1819-1833 (Madrid, 1933); Juan Antonio Gaya Nuño, Historia del Museo del Prado.1819-1969 (León, 1969); Pérez Sánchez 1977, ibid; Antonio Rumeu de Armas, Origen y Fundación del Museo del Prado (Madrid, 1980); Santiago Alcolea, Museo del Prado (Bar-
}

AEA, LXXVIII, 2005, 309, pp. 59 a 69 
la escultura neoclásica española ${ }^{14}$, esta primerísima exposición de estatuas modernas ha pasado desapercibida, o como ocurre en el caso de Mariano de Madrazo, contada de manera extremadamente confusa. En su Historia del Museo del Prado 1818-1868, Madrazo confunde la posterior exposición del famoso grupo escultórico de Álvarez titulado la Defensa de Zarago$z a$, llegado a Madrid desde Roma en julio de 1827 y también expuesto en el museo gracias al consentimiento real ${ }^{15}$, con esos dos retratos de los padres del rey mostrados al público a principios del año. Este autor relata —erróneamente—que «en 1827...el día 8 [de julio] ... llegó de Roma el grupo en marmol hecho por el escultor de S.M. representando a los Reyes padres, obra de don Ramón Barba...» y que «el grupo escultórico de SS.MM.» fue expuesto en el museo «en octubre [de 1827]... temporalmente, por término de un mes». Cuenta además que «el grupo... representando a los Reyes padres» fue colocado en un «pedestal giratorio» ${ }^{16}$, mecanismo que sin embargo no aparece descrito en ninguno de los documentos actualmente conocidos referentes a las dos estatuas independientes de Carlos IV y María Luisa.

Otra confusión introducida en los mismos documentos de la época puede haber desorientado a los investigadores subsiguientes sobre la identidad de las piezas: en la correspondencia referente al transporte de estas dos obras grandes y pesadas, se alude extrañamente a ellas como «bustos» (quizá un término empleado equivocadamente como sinónimo de «retratos»), hasta que ya en Madrid Álvarez las describe como «estatuas» ${ }^{17}$. Además, una nota anónima del mismo período conservada en el expediente del archivo del Prado corrige explícitamente la terminología: «Los dos bustos que se expresan son dos Estatuas de Cuerpo entero que representan a los $S .{ }^{\text {res }}$ Reyes Padres...ejecutadas en marmol de Carrara...». En el mismo apunte se aclara también la doble autoría de la pareja de obras, pero ésta es otra equivocación que persistió, siendo ambas atribuidas únicamente a uno u otro de los dos artistas en varias ocasiones sucesivas ${ }^{18}$.

Significativamente, esta primera muestra de esculturas en el museo durante su «época constituyente», tiene lugar justo en el momento en que se había empezado a elegir obras escultóricas de las colecciones reales para su posible exposición permanente dentro de lo que pronto se convertiría en museo de pinturas y esculturas. El 22 de julio de 1826, el escultor Álvarez había sido comisionado por el duque de Hijar «para examinar...las estatuas y demas objetos de su arte que por su belleza sea justo sacar de los sôtanos y otros puntos en que se hallan custodiados», y el 7 de octubre de 1826 el artista ya tenía compuesta una lista de las piezas seleccionadas ${ }^{19}$. El hecho refleja asimismo el debate académico de la época sobre «la primacia de

celona, 1991); Javier Portús, Museo del Prado. Memoria Escrita. 1819-1994 (Madrid, 1994); Gonzalo Anes, Las Colecciones Reales y la Fundación del Museo del Prado (Madrid, 1996).

${ }^{14}$ Véase, por ejemplo, de Enrique Pardo Canalís: Escultores del Siglo XIX (Madrid, 1951); Escultura Neoclásica Española (Madrid, 1958); y «Estancia en Roma del Escultor Ramón Barba», Revista de Ideas Estéticas, 25:97 (1967), pp. 45-64.

${ }_{15}$ AGP, Reinados, Fernando VII, caja 401, exp. 81: 3 documentos fechados entre el 13 y el 20/VII/1827.

${ }^{16}$ Mariano de Madrazo, Historia del Museo del Prado 1818-1868 (Madrid, 1945), p 113. Se recopila esta información en: Margarita Heredia Plaza, Patrimonio Escultórico del Museo del Prado, 2 tomos, tesis doctoral inédita, Facultad de Bellas Artes, UCM (Madrid, 1989), I, p. 244.

${ }_{17}$ AGP, EP, José Álvarez, caja 67, exp. 3, doc. 73: Álvarez a Blasco (19/VIII/1826).

${ }^{18}$ Eg: Madrazo 1945, op. cit. nota 16 supra, p. 113, atribuye el «grupo» a Barba; en Tesoro de la Escultura. Colección Fotográfica de las mejores obras existentes en el Real Museo y fuera de él, anotada por Francisco Muñoz y Ruiz y José Sala y Sardá (y Manuel Ossorio y Bernard en el t. I), 4 tomos (Madrid 1862-1864), IV, pp. 109 y 111, y en El Conde de la Viñaza, Adiciones al Diccionario Histórico de los más ilustres Profesores de la Bellas Artes en España, 4 tomos (Madrid, 1889-1894), II, p. 47, ambas estatuas están atribuidas a Barba; en Manuel Ossorio y Bernard,Galería Biográfica de Artistas Españoles del Siglo XIX (Madrid, 1975 = ed. facsímil de la $2^{a}$ ed. 1883-1884; la $1^{\text {a }}$ ed. = 1868-1869), pp. 31 y 68, bajo la voz «Álvarez», ambas esculturas están atribuidas a él, pero bajo la voz «Barba» ambas están atribuidas también a este escultor.

${ }^{19}$ Beroqui 1933, op. cit. nota 13 supra, p. 114; y Heredia 1989, op. cit. nota 16 supra, I, p. 243 . El 15 de noviembre de 1829 se afirma que «en el Real Museo de Pinturas...se esta formando con el mayor esmero e interes una Galeria de Estatuas y otros objetos de Escultura» (AMP, caja 357, leg. 46, núm. 4). 
las bellas artes, y de cual sea mas noble la Escultura ó la Pintura». El respetado entendido Juan Agustín Ceán Bermúdez propuso en un didáctico diálogo imaginario publicado en 1822, que «se declara ser iguales en mérito, distinciones y prerogativas estas dos hermanas gemelas» ${ }^{20}$. Seguramente esta actitud influyó en el duque de Hijar a la hora de tomar la decisión de empezar a exponer esculturas en el museo, tanto de forma temporal como permanente.

La prueba de la envergadura de esta exposición inicial de mármoles se halla precisamente en que el curioso Slidell no sólo pasó por el museo a verla, sino que la mencionó en su libro, siendo por otra parte el único evento artístico contemporáneo que cuenta haber tenido lugar durante su estancia en Madrid. Entre los previsiblemente numerosos ${ }^{21}$ visitantes «nacionales y extrangeros» que pasaron a contemplar las estatuas (pero que, al contrario que el marinero no dejaron constancia escrita de sus opiniones), Slidell resultó ser un testigo con ciertos prejuicios. Sus comentarios demuestran que a veces es absolutamente imposible separar el arte de la política, dado que como buen republicano norteamericano, el antimonárquico Slidell censura la estatua de Carlos $I V$, en la que el rey aparece vestido a modo de emperador romano. Insinúa que el artista ha idealizado y ennoblecido con su cincel a un alma innoble, y opina -en tono bastante indignado- que «su efigie casi podría tomarse por la de Washington», el venerado padre fundador de la nueva nación democrática. El viajero concluye su crítica con una frase airada: «Una admiración así inducida con engaño, es motivo casi suficiente para renegar de la escultura» ${ }^{22}$.

Ahora bien, aunque suenan algo fogosas, las observaciones de Slidell no carecen de relevancia respecto del estilo neoclásico internacional de escultura entonces imperante. En efecto, George Washington ya había sido representado vestido a la romana por el italiano Antonio Canova (1757-1822), y volvió a serlo a la sazón por el norteamericano Horatio Greenough (1805-1852), cuyo taller de Boston Slidell pudo haber visitado en 1828, de vuelta de su periplo por España ${ }^{23}$. En los Estados Unidos, Slidell pudo haber conocido desde su infancia tanto estatuas como estampas basadas en retratos pintados o esculpidos de Washington, que se hallaban en todos los hogares según testimoniaba en 1811 un viajero ruso ${ }^{24}$. Por otro lado, tanto Álvarez como Barba seguían escrupulosamente los cánones neoclásicos, repletos de referencias a obras antiguas y de idealizaciones de personajes contemporáneos, tal y como habían sido establecidos en Roma en el último cuarto del siglo xviII por el jefe de escuela Canova. Así que es comprensible que para Slidell la estatua de Barba desprendiera un aire que le hacía recordar ciertas esculturas de Washington, y quizás concretamente, una obra esculpida por Canova entre 1817 y 1821 (Fig. 3) ${ }^{25}$. Tanto la escultura de Barba como ésta de Canova parecen estar

${ }^{20}$ Juan Agustín Ceán Bermúdez, Bellas Artes. Diálogo sobre la primacia entre La Pintura y La Escultura (Madrid, 1822), p. 30, encuadernado en Ocios de D. Juan Agustin Cean-Bermudez sobre Bellas Artes. Madrid, 1822. Véase también: Celedonio Arce y Cacho, Conversaciones sobre la escultura [Pamplona, 1786], ed. facsímil de Cristóbal Belda Navarro. Murcia, 1997.

${ }^{21}$ No han sobrevivido noticias sobre la cantidad de visitantes a esta presentación, pero sí se sabe, gracias a una comunicación del duque de Hijar, que cuando llegó en julio de 1827 la Defensa de Zaragoza por Álvarez, hubo un enorme y contínuo interés por parte de «infinitas personas de la primera distincion...para examinar las bellezas de la referida obra» (AGP, Reinados, Fernando VII, caja 401, exp. 81; Hijar a Blasco, 13/VII/1827).

${ }^{22}$ El texto completo en inglés: «During my residence in Madrid, statues arrived from Rome of Charles IV. and his queen Maria Luisa, beautifully executed by Spanish artists. If the chisel of the statuary was not flattered, [sic] Charles IV. was not less noble in person than ignoble in character. His statue might almost be taken for that of Washington. Whoever, therefore, may chance to see this marble image, will have something to qualify his detestation of the original. To be thus cheated into admiration were almost enough to make one quarrel with statuary» (Slidell 1831, op. cit. nota 1 supra, II, p. 317).

${ }^{23}$ Véase: Richard H. Saunders, Horatio Greenough. An American Sculptor's Drawings, cat. expo. Middlebury College Museum of Art (Middlebury, Vermont, 1999), p. 88.

${ }^{24}$ Saunders 1999 , ibid, p. 85.

${ }^{25}$ Gipsoteca Canoviana, Possagno, núm. 265, 1818, escayola, altura $160 \mathrm{~cm}$; encargada para el Capitolio de Raleigh, Carolina del Norte, la versión en mármol fue inaugurada en 1821, pero destruida en el incendio de 1831; sobreviven los dibujos y los modelos de escayola. Véase: Antonio Canova, The Works of Antonio Canova in Sculpture and Modelling,

$A E A$, LXXVIII, 2005, 309, pp. 59 a 69 
relacionadas con la colosal estatua sedente del emperador romano Tiberio que se hallaba en el Museo Chiaramonti del Vaticano, obra antigua que puede haber servido de fuente de inspiración para ambos retratos neoclásicos (Fig. 4) ${ }^{26}$.

A su vez, la estatua hecha por Álvarez de María Luisa de Parma, vestida «con vagos ropajes de estilo Imperio, suficientemente vagos para que puedan confundirse con vestas romanas ${ }^{27}$, recuerda antiguas efigies de musas también expuestas en el Museo Chiaramonti, como la llamada Poetisa (Fig. 5) ${ }^{28}$, y en el Museo Pio Clementino del Vaticano, como la Musa Clío (Fig. 6) ${ }^{29}$. Es más, la estatua de la Reina Madre es sumamente (casi sospechosamente) semejante en cuanto a concepto y pose a la estatua coetánea de la segunda esposa de Napoleón, Marie Louise de Habsburgo como La Concordia, elaborada por Canova entre 1809 y 1814 (Fig. 7) ${ }^{30}$. Como indicaba en 1816 el entonces embajador en París Thomas Jefferson en relación con otra proyectada estatua de Washington: «En cuanto a estilo o vestido, estoy seguro de que el artista y toda persona de gusto en Europa optaría por lo romano» ${ }^{31}$.

Por supuesto (y eso no podía saberlo el joven marino que visitaba Madrid), en la Academia de San Fernando la necesidad de estudiar el arte antiguo se entendió desde sus comienzos a mediados del siglo xvIII, y Ceán recuerda este requisito todavía en 1822, cuando en su diálogo ficticio sobre la escultura pone en boca de Alonso Cano el dictamen: «...ningun escultor hará grandes progresos sin estudiar el antiguo» ${ }^{32}$. Justamente, Álvarez y Barba habían asimilado ampliamente las reglas académicas, y ambos -pero sobre todo el primero- gozaban de la alta estima de sus contemporáneos. Cabe señalar también que los dos artistas daban mucha importancia a esas obras suyas: Álvarez contó su Maria Luisa de Parma «entre los principales» logros de toda su producción ${ }^{33}$, y Barba pensaba que el «encargo dificil» de esculpir una «estatua grande de cuerpo entero» de Carlos IV iba a «eternizar la memoria de un Rey sabio, pio, clemente, y justo» ${ }^{34}$. En recompensa por sus esfuerzos, el retrato póstumo de Álvarez, esculpido por Barba, figura entre los medallones con retratos de artistas españoles encargados para decorar la fachada del museo, y fue precisamente Ceán quien propuso, en noviembre de

engraved in outline by Henry Moses, 3 tomos (Londres, 1824-1828), I, cronología 1818; Fred Licht, Canova (Nueva York, 1983), pp. 104-107; y Mario Praz y Giuseppe Pavanello, L'opera completa del Canova (Milano, 1976), núms. $301-306$.

${ }^{26}$ Museo Chiaramonti, Vaticano, núm. 400, h. 14-37 d.C, altura $200 \mathrm{~cm}$. Véase: Deutsches Archäologisches Institut. Bildkatalog der Skulpturen des Vatikanischen Museums. Museo Chiaramonti, 3 tomos (Berlín/Nueva York, 1995), I, p. 165.

27 Juan Antonio Gaya Nuño, Arte del Siglo XIX. Ars Hispaniae, t. 19 (Madrid, 1958), p. 75.

${ }^{28}$ Museo Chiaramonti, Vaticano, núm. 121, estatua romana de la época Antonina, basada en una obra griega del siglo IV a. C, altura $153 \mathrm{~cm}$. Véase: Deutsches 1995, op.cit. nota 26 supra, II, p. 776.

${ }^{29}$ Ennio Quirino Visconti, Il Museo Pio Clementino, 7 tomos (Milano, 1818-1822), II (1819), pl. 24.

${ }^{30}$ Galleria Nazionale, Parma, mármol, altura $173 \mathrm{~cm}$. Véase: Canova 1824-1828, op. cit. nota 25 supra, I, cronología 1811; Licht 1983, op. cit. nota 25 supra, pp. 145-151; Praz y Pavanello 1976, op. cit. nota 25 supra, núm. 226; y Christopher M.S. Johns, Antonio Canova and the Politics of Patronage in Revolutionary and Napoleonic Europe (Berkeley, 1998), pp. 107-108.

${ }^{31}$ "As to the style or costume, I am sure that the artist and every person of taste in Europe would be for the Roman" (carta de Jefferson [1743-1826] del 22/I/1816, citada en: Hjorvardur Harvard Arnason, The Sculptures of Houdon [Londres, 1975], p. 74). En vida, Washington (1732-1799) se negó a ser representado all'antica, y su primer retratista europeo famoso, Jean-Antoine Houdon (1741-1828), tuvo que representarle con ropa contemporánea en su estatua de cuerpo entero destinada al Capitolio de Richmond, Virginia, de 1785-1788 (Arnason 1975, pp. 72-76). Para el corpus retratístico de Washington véase: Gustavus A. Eisen, Portraits of Washington, 3 tomos. Nueva York, 1932. Para Houdon véase también: Louis Réau, Houdon, sa vie et son oeuvre, 2 tomos. París, 1964; y Anne Poulet, Guilhem Scherf et al. Houdon, sculpteur des Lumières (1741-1828), cat. expo. Château de Versailles. Réunion des Musées Nationaux, París, 2004.

${ }^{32}$ Ceán 1822 , op cit. nota 20 supra, p. 4.

${ }^{33}$ AGP, EP, Álvarez, caja 67, exp. 3, memorial del 27/II/1823, dirigido por el artista a Fernando VII. Véase también: Enrique Serrano Fatigati, «Escultura en Madrid desde mediados del siglo XVI hasta nuestros días», Boletín de la Sociedad Española de Excursiones, t. 18 (sept. de 1910), p. 166, donde cita una carta del 19/XI/1819 en que Álvarez considera esta escultura «entre sus obras más capitales».

${ }^{34}$ AGP, EP, Álvarez, caja 67, exp. 3, doc. 99, memorial de Barba a Fernando VII, del 1/IX/1816, archivado en el EP de Álvarez, en vez de en el de Barba; publicado entero por Pardo Canalís 1951, op. cit. nota 14 supra, pp. 241-242. 

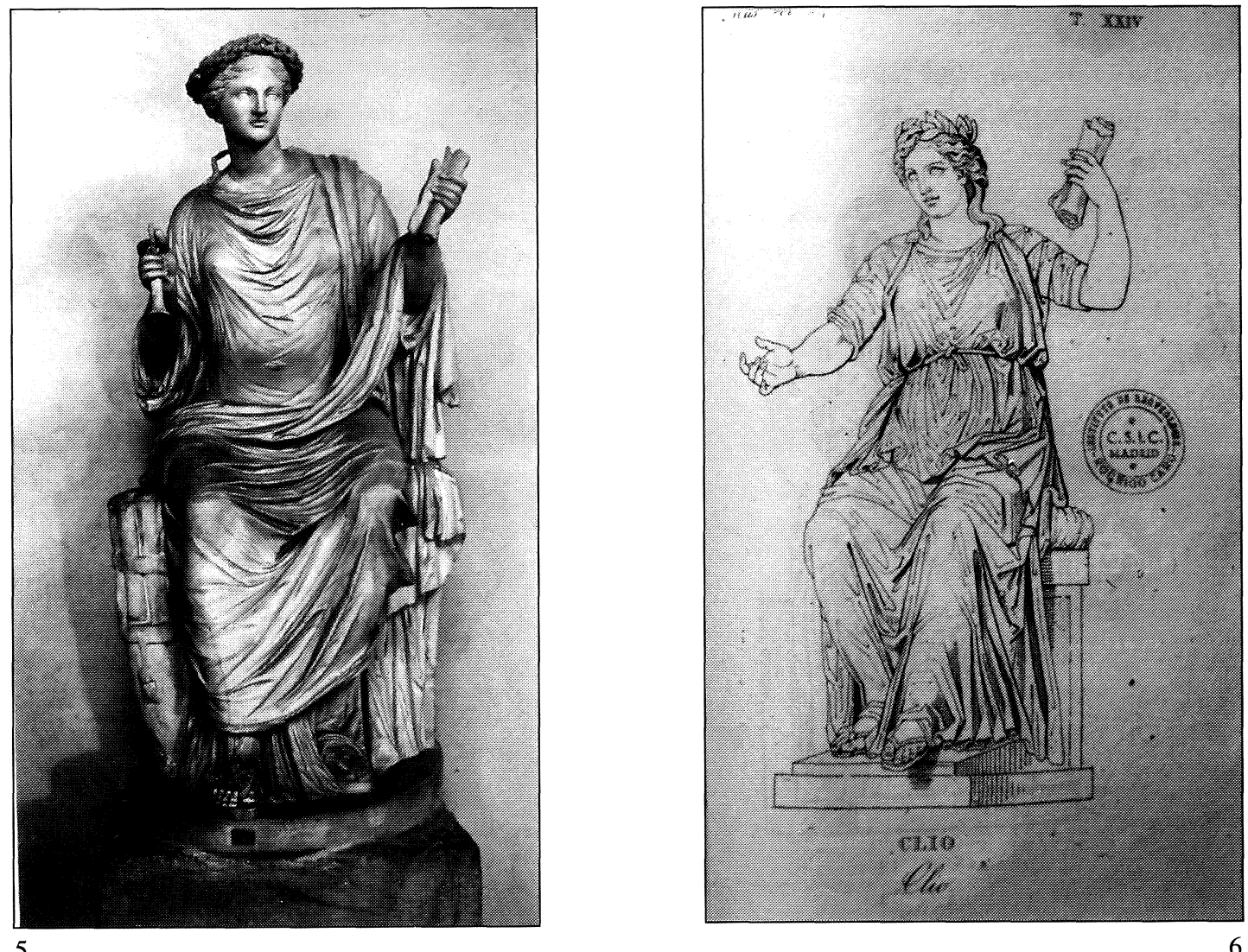

5

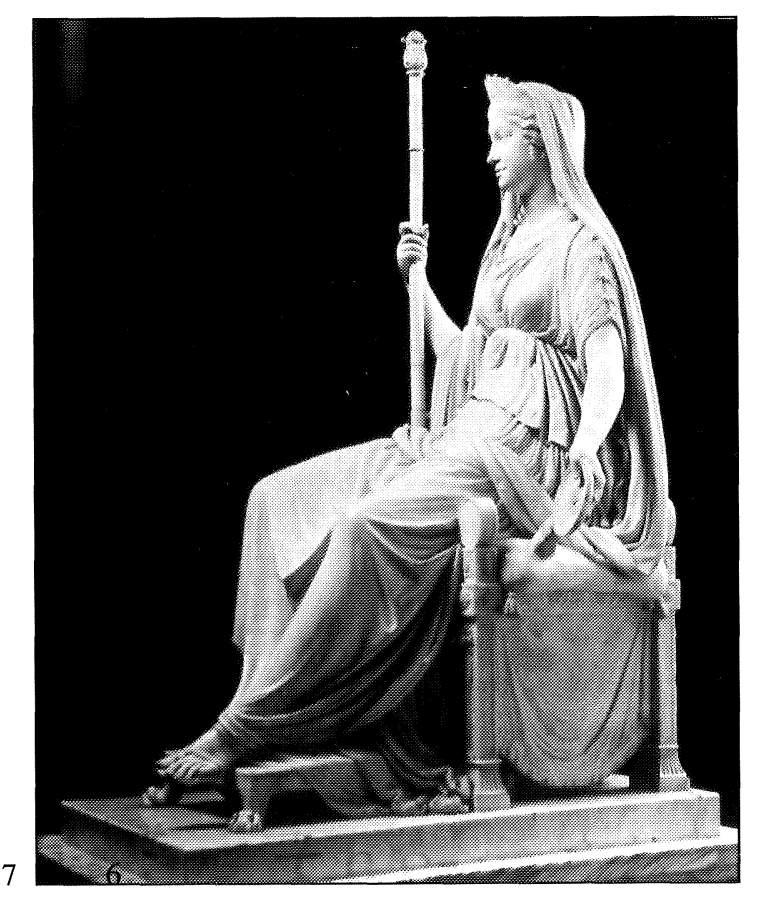

Fig. 5. Anónimo romano, Poetisa, h. 100 d.C., mármol, Museo Chiaramonti, Vaticano, Roma, núm. 121.

Fig. 6. Anónimo romano, La Musa Clío, estampa de h. 1818, que reproduce una estatua antigua del Museo Clementino, Vaticano, Roma.

Fig. 7. Antonio Canova, Marie Louise de Habsburgo, como la Concordia, 1814, mármol,Galleria Nazionale, Parma.

AEA, LXXVIII, 2005, 309, pp. 59 a 69 
1828, que la imagen de Álvarez estuviera en ese lugar de honor ${ }^{35}$. Después de su muerte, la biografía de Álvarez se publicó en el Semanario Pintoresco ${ }^{36}$, y el artista fue elogiado en la Academia de San Fernando por el Duque de Frías en una oda Á las Nobles Artes leída el 27 de marzo de 1832, que refleja el ambiente de la época:

\section{"¡Álvarez inmortal! tambien tu genio \\ En la ciudad de Rómulo famosa \\ Supo un tiempo brillar; la tumba umbría \\ Hoy te cubre á mis ojos, \\ Mas no á la Gloria de la patria mia ${ }^{37 " . ~}$}

Las figuras de los Reyes Padres, tras su primera presentación al público en una exposición temporal de 15 días de duración, no salieron del museo, sino que fueron bajadas a la planta inferior, donde se proyectaba exponer la colección real de esculturas antiguas y modernas, con al principio, acceso exclusivo desde el lado sur del edificio (actualmente la puerta de Murillo). Ya en 1831 Ramón de Mesonero Romanos informa de la presencia «en la galería larga» de la estatua «del rey Carlos IV por Barba» ${ }^{38}$. En 1834 ambas obras aparecen en el folio 29 del «Inventario y Tasación de las Estatuas Bustos [sic] y demas objetos de escultura pertenecientes a S.M. que se hallan en las Galerías del Real Museo» ${ }^{39}$, aunque sin indicación exacta de la sala en que fueron ubicadas. Son citadas de nuevo con los números 529 y 532 del inventario del museo redactado entre 1849 y 1857 , pero otra vez sin datos relativos a su instalación ${ }^{40}$. La primera referencia segura al emplazamiento de ambas obras dentro de la colección permanente figura en un tomo publicado en 1864, en el cual se señala que estaban colocadas en el salón de escultura «de la izquierda» ${ }^{41}$, o norte, dado que a partir de por lo menos 1839 , según el testimonio de Valentín Carderera, la entrada a las galerías de escultura se efectuaba desde el paseo del Prado (actualmente la puerta de Velázquez) ${ }^{42}$. De esta fecha, o un poco antes, datan las primeras fotografías conocidas de estas piezas, realizadas en tomas individuales (Figs. 1 y 2 ) $^{43}$ y también en una singular vista estereoscópica de la galería norte de la planta baja, en la que se hallaban —en posición destacada - centradas entre otras obras tanto clásicas como neoclásicas (Fig. 8) ${ }^{44}$. Su suerte entre 1868 y 1894 no está del todo clara, dado que muchas imágenes de los Borbones fueron retiradas de las galerías y llevadas a los almacenes a raíz de la Revo-

\footnotetext{
${ }^{35}$ AMP, caja 357, leg. 47, núms. 5 y 6. Véase también: Pedro Beroqui, «Apuntes para la historia del Museo del Prado», Boletín de la Sociedad Española de Excursiones, vol. 40 (marzo de 1932), pp. 16-18.

${ }^{36}$ E. de O., «Don José Alvarez», Semanario Pintoresco, vol. II (1837), pp. 100-102.

${ }^{37}$ Bernardino Fernández de Velasco, duque de Frías (1783-1851), Á las Nobles Artes. Oda (Madrid, 1832 ), p. 10.

${ }^{38}$ Ramón de Mesonero Romanos. Manual de Madrid. Descripción de la Corte y de la Villa (Madrid, 1831), p. 217 (se repite en la edición de 1833 , p. 225).

${ }^{39}$ Este inventario forma parte de las Testamentarías de Fernando VII; está publicado en Anes 1996, op. cit. nota 13 supra, pp. $315 \mathrm{ff}$.

40 «Ynventario general de objetos artísticos y efectos de todas clases ecsistentes [sic] en el Real Museo de Pintura y Escultura de S.M.» (Madrid, 1849-1857), f. 739.

${ }^{41}$ Tesoro 1862-1864, op. cit. nota 18 supra, IV, pp. 109 y 111.

42 Valentín Carderera. «Exposición del Real Museo (artículo segundo). Galería de Escultura», Semanario Pintoresco Español, segunda série, t. I, núm. 19 (12 de mayo de 1839), pp. 151-152: «La magnífica galería de escultura ocupa el piso bajo, y casi toda la longitud del suntuosísimo Museo Real...Entrando por el gran pórtico de la fachada principal...En el gran salon, á la derecha del que entra por el citado portico...El otro gran salon colateral de la izquierda...».

${ }^{43}$ Publicadas por primera vez en Tesoro 1862-1864, ibid, IV (1864), pp. 110 y 112; no llevan el nombre del fotógrafo. Tesoro está catalogado en Isabel Ortega y Gerardo Kurtz, 150 Años de Fotografía en la Biblioteca Nacional, cat. expo. Biblioteca Nacional (Madrid, 1989), p. 126.

${ }^{44}$ Identificada en el pie: «Intérieur de la galerie de sculpture, 2665. Au Musée de Madrid - J.A.»; descubierta por José Manuel Matilla durante los preparativos para la exposición El Grafoscopio. Un siglo de miradas al Museo del Prado (1819. 1920), cat. expo. Museo del Prado (Madrid, 2004), cat. núm. 33 (p. 295); fig. 84 (p. 113).
}

$A E A$, LXXVIII, 2005, 309, pp. 59 a 69 


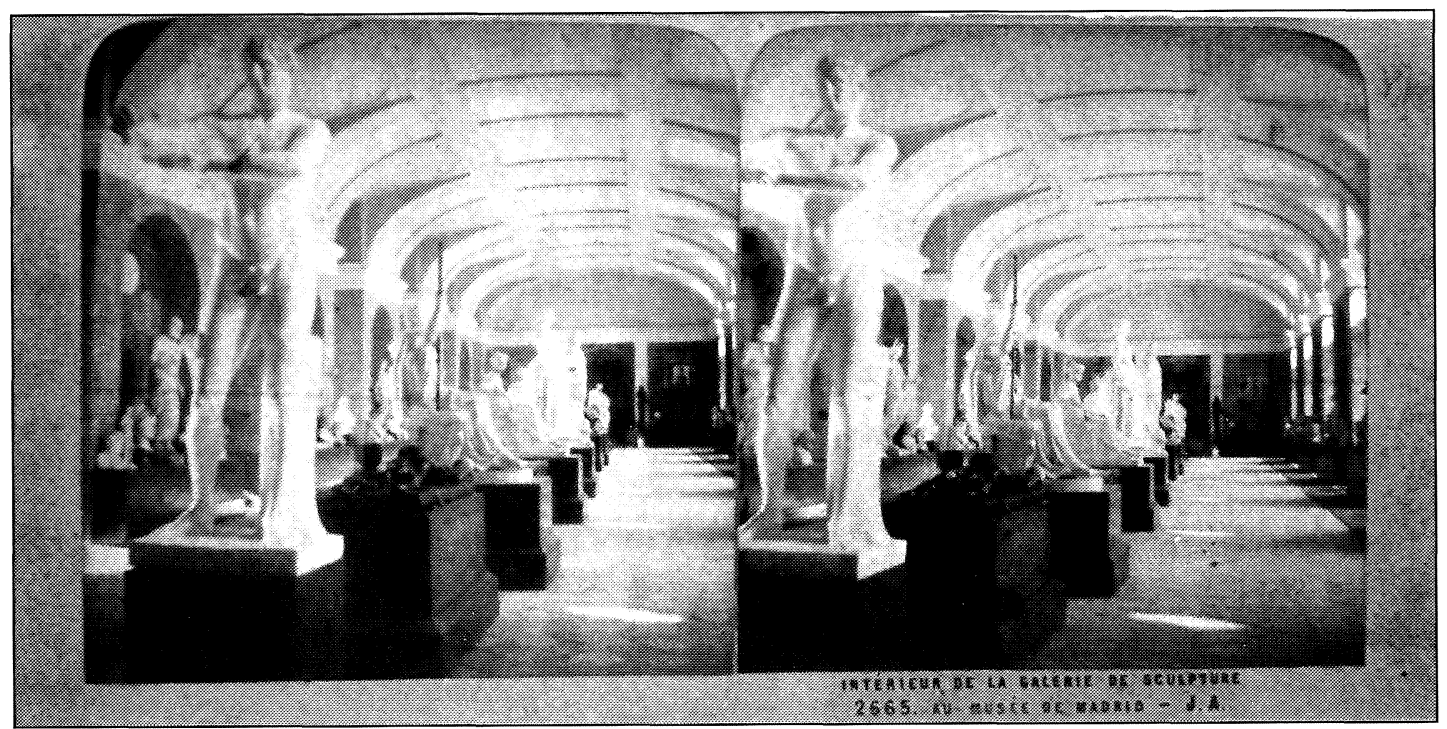

8

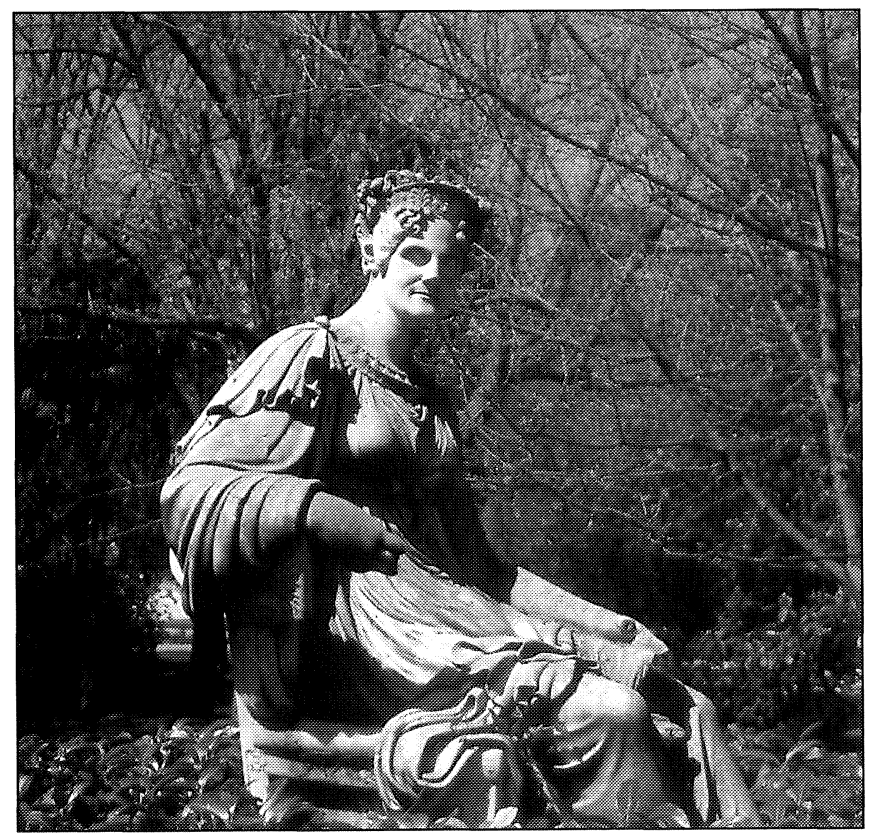

Fig. 8. Jules Andriev, Galería norte de escultura, Museo del Prado, Fotografía estereoscópica, h. 1862, Colección Madridantique.

Fig. 9. José Álvarez, María Luisa de Parma, sedente, 1816, mármol de Carrara, en su emplazamiento en el Campo del Moro, Madrid, abril de 2004.

Fig. 10. José Álvarez, María Luisa de Parma, sedente, abril de 2004.

AEA, LXXVIII, 2005, 309, pp. 59 a 69 
lución de 1868 , la primera República y la nacionalización de las colecciones reales ${ }^{45}$. A partir de 1894, se sabe que fueron trasladadas al recién creado Museo de Arte Moderno, ubicado en «toda la planta alta de la fachada principal» ${ }^{46}$ de la Biblioteca Nacional, donde fueron fotografiadas de nuevo, esta vez por José Moreno, a principios del siglo $\mathrm{xx}^{47}$. Con la disolución de esta institución en 1971, las estatuas pasaron en calidad de depósito del Museo del Prado al Patrimonio Nacional, bajo cuyo control estuvieron durante una temporada en el Palacio de la Quinta, y actualmente se encuentran en el Palacio Real de Madrid (Carlos IV) y en los jardines del Campo del Moro (María Luisa), esta última a la intemperie y literalmente rodeada por un arbusto (Figs. 9 y 10$)^{48}$.

Esta temprana exposición, realizada con el beneplácito del Rey, fue un acontecimiento artístico y social excepcional en el Madrid de la época. Por un lado, demuestra la voluntad del monarca de realzar su nuevo museo, y por otro manifesta su voluntad política de admitir el regreso simbólico de sus padres a España, para ser debidamente honrados, ocho años después del fallecimiento de ambos en el extranjero. Con estas dos estatuas se duplicaba la presencia de Carlos IV y María Luisa en el museo, dado que sus retratos ecuestres pintados por Goya habían estado colgados en las primeras salas abiertas al público desde su inauguración el 19 de noviembre de $1819^{49}$. La nueva muestra de sus imágenes en mármol de Carrara permitía al absolutista Fernando, durante la llamada «década ominosa» de su reinado, recordar a sus súbditos su propio linaje y su derecho hereditario al trono. Desde el punto de vista artístico, estos dos escultores de Cámara habían sido generosamente subvencionados por la Corona durante años en Roma, y en la época analizada estaban comprometidos en la tarea de ampliar las colecciones del Real Museo, además de ejecutar la decoración escultórica del exterior del edificio de Villanueva. Así que esta primera presencia de esculturas en el Real Museo de Pinturas fue un acontecimiento tanto de conveniencia política como de deleite estético en el estilo moderno del neoclasicismo internacional.

\footnotetext{
${ }^{45}$ Ángel Fernández de los Ríos (Guía de Madrid, Manual del Madrileño y del Forastero. Madrid, 1876, p. 498), publica una xilografía del «Salón de escultura» del museo, donde no parecen figurar estas estatuas; además, aparentemente es una vista de la galería sur.

${ }^{46}$ Joaquin de la Puente, «Museo Español de Arte Contemporáneo», Reales Sitios, año VI, número extraordinario dedicado a los Museos de Madrid (1969), p. 44. Véase también: Catálogo Provisional del Museo de Arte Moderno, segunda edición oficial (Madrid, 1900), p. 104, núms. 7 y 12.

${ }^{47}$ Archivo Moreno negativos núms. 00542-B y 00543-B; reproducidos en Pardo Canalis 1951, figs. 41 y 49; y 1958, láms. 20 y 29 , ops. cits. nota 14 supra.

${ }^{48}$ Como se ve en estas fotos del 7/IV/2004, la escultura de Álvarez se halla en lámentable estado. La punta de la nariz y ambas manos de la estatua de María Luisa están rotas, falta el cetro que llevaba en la mano derecha, y el mármol blanco está sucísimo. Coincidiendo con la impresión de este artículo (3/III/2005), tengo noticia de que se proyecta retirar la escultura del Campo del Moro, restaurarla y trasladarla a un sitio más apropiado.

${ }^{49}$ Museo del Prado, núms. 719 y 720. Eusebi 1819, op. cit. nota 12 supra, p. 20: están en el «Salón tercero»; Eusebi 1821, op. cit. nota 12 supra, p. 20: están en el «Salón del centro»; Eusebi 1828, op. cit. nota 12 supra, p. 67: están en la «Entrada ó primera división de la Gran galería de en medio». Los dos retratos de pie de los monarcas por Goya-Esteve (Museo del Prado, núms. 727 y 728) también pasaron al museo antes de 1834, pero se colocaron en el «Gabinete de Descanso de SS.MM.» y no en una sala pública («Inventario general...»1834, ff. 419-419v, en Anes 1996, op. cit. nota 13 supra, pp. 195 y 197).
}

AEA, LXXVIII, 2005, 309, pp. 59 a 69 